STUDI

FRANCESI

\section{Studi Francesi}

Rivista quadrimestrale fondata da Franco Simone

185 (LXII | II) | 2018

OCTAVE MIRBEAU: UNE CONSCIENCE AU TOURNANT

DU SIEECLE - sous la direction de Ida Merello

\title{
VINCENT LAISNEY, En lisant en écoutant. Lectures en petit comité, de Hugo à Mallarmé
}

\section{Michel Arrous}

\section{(2) OpenEdition \\ Journals}

Édition électronique

URL : https://journals.openedition.org/studifrancesi/13727

DOI : $10.4000 /$ studifrancesi. 13727

ISSN : 2421-5856

Éditeur

Rosenberg \& Sellier

Édition imprimée

Date de publication : 1 août 2018

Pagination : 332

ISSN : 0039-2944

\section{Référence électronique}

Michel Arrous, " VINCENT LAISNEY, En lisant en écoutant. Lectures en petit comité, de Hugo à Mallarmé », Studi Francesi [En ligne], 185 (LXII | II) | 2018, mis en ligne le 01 août 2018, consulté le 15 novembre 2021. URL : http://journals.openedition.org/studifrancesi/13727; DOI : https://doi.org/10.4000/ studifrancesi. 13727

Ce document a été généré automatiquement le 15 novembre 2021.

\section{(c)}

Studi Francesi è distribuita con Licenza Creative Commons Attribuzione - Non commerciale - Non opere derivate 4.0 Internazionale. 


\title{
VINCENT LAISNEY, En lisant en écoutant. Lectures en petit comité, de Hugo à Mallarmé
}

\author{
Michel Arrous
}

\section{RÉFÉRENCE}

VINCENT LAISNEY, En lisant en écoutant. Lectures en petit comité, de Hugo à Mallarmé, Paris, Les Impressions Nouvelles, 2017, 219 pp.

1 L'histoire de la lecture à haute voix en cercle restreint au XIX siècle n'ayant pas encore été écrite, Vincent Laisney a enquêté afin d'en retracer les étapes essentielles. Cette pratique sans véritable protocole, il ne faut pas la confondre avec les redoutables lectures dans les salons, aristocratiques ou non, d'ailleurs abondamment documentées et dont Balzac a dit qu'elles étaient un malheur auquel ne pouvaient échapper ni un homme du monde ni une femme à la mode; encore moins avec les lectures officielles devant un comité de professionnels (comédiens, directeurs de théâtres). À l'origine des investigations, le tableau de Théo van Rysselberghe intitulé Une Lecture (1903) - titre initial: La Lecture par Émile Verhaeren - dont la genèse est connue: Verhaeren lit ses vers en les scandant du bras à un public d'élite composé de Gide, Maeterlinck et de cinq autres protagonistes oubliés aujourd'hui mais dont l'attitude est également valorisée. Il s'agit d'une authentique séance de lecture à haute voix dans le salon bourgeois du poète, plutôt que d'un arrangement, d'une allégorie ou d'un hommage à la manière de Fantin-Latour. Victime d'une mauvaise information - une blague belge? - le détective ne verra pas la toile à Gand et devra se contenter d'une reproduction.

Cette pratique culturelle connut son âge d'or entre 1824 et 1834, après l'abandon des lectures trop longues (citons les 24000 vers du Philippe-Auguste de ParsevalGrandmaison sous la Restauration); à la fin du siècle elle n'avait rien perdu de sa vitalité, si bien qu'on peut voir dans les lectures de la période post-symboliste un 
«archétype de la lecture littéraire à haute voix», sans excepter les spectacles poétiques sous la houlette de Paul Fort de 1890 à 1893. La plupart des écrivains ont partagé l'habitude de soumettre leurs essais à un petit nombre de confrères, c'est ce qu'illustre le tableau choisi et qu'avaient déjà signalé Sainte-Beuve et Nerval en 1832, Mme Daudet en 1882. Cénacle ou petit comité, l'opération a pour but de recueillir l'avis d'amis ou de pairs, de s'assurer que l'œuvre est viable ou de comprendre qu'elle doit être perfectionnée. C'est notamment le cas des apprentis qui retravaillent leurs manuscrits sur la suggestion d'une autorité, Nodier ou Hugo; c'est aussi celui de Flaubert en 1849 pour le "crash test" de La Tentation de saint Antoine qui consterna Du Camp et Boullhet. Lors de ces "performances», les uns fascinent leur auditoire (Hugo, Musset, Baudelaire, Edmond de Goncourt, Villiers), les autres souffrent en silence (applaudie chez Hugo, «La Frégate» de Vigny fait naufrage chez Mme d'Agoult; le «Bhagavat» de Leconte de Lisle pétrifie les invitées) ou bien protestent (Mallarmé), jusqu'à provoquer un esclandre (Rimbaud). On pourrait ajouter le cas plus rare de ceux qui s'épuisent nerveusement (Constant lisant Adolphe en 1817), ou qui trompent leur auditoire (Mérimée lisant Lokis en 1869). Esquissant une sémiologie de la lecture, V. Laisney n'oublie donc pas le lecteur, qu'il lise ses propres œuvres ou celles d'un confrère. Même s'il arrive que les poètes ne soient pas les mieux placés pour dire leurs œuvres, on voit que les professionnels, formatés ou non par le Conservatoire, ne l'emportent pas toujours sur les «lecteurs de charme». Les exemples des diverses méthodes pour tester les œuvres ne manquent pas, que l'on soit dans le «grenier» de Delécluze (les scènes d'anthologie qui émaillèrent les matinées de «M. Chabannais» auraient pu être évoquées) ou dans son opposé parfait, le salon de Mme Récamier où, pendant trente ans, se succédèrent devant une élite parisienne des lectures dont l'écho nous est parvenu grâce à Latouche, Lamartine, Ballanche, Sainte-Beuve, Janin.

3 Érudite mais jamais pesante, cette évocation au fil de 80 brefs chapitres a aussi le mérite d'aborder l'art de la diction et de nous inciter à écouter à nouveau la voix de Verhaeren ou d'Apollinaire enregistrée à l'initiative de F. Brunot, dans des circonstances hélas bien différentes du rite désormais archaïque d'une lecture réservée à quelques amis... 